\title{
Atmospheric transport of persistent semi-volatile organic chemicals to the Arctic and cold condensation in the mid-troposphere - Part 2: 3-D modeling of episodic atmospheric transport
}

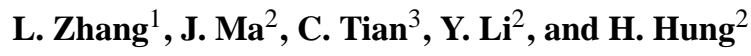 \\ ${ }^{1}$ Lamu Environment, 41 Mountfield Crescent, Thornhill, Ontario L4J 7E9, Canada \\ ${ }^{2}$ Air Quality Research Division, Environment Canada. 4905 Dufferin Street, Toronto, Ontario M3H 5T4, Canada \\ ${ }^{3}$ School of Municipal and Environmental Engineering, Harbin Institute of Technology, China
}

Received: 27 August 2009 - Published in Atmos. Chem. Phys. Discuss.: 10 December 2009

Revised: 15 February 2010 - Accepted: 20 February 2010 - Published: 9 August 2010

\begin{abstract}
Two 3-dimensional global atmospheric transport models for persistent organic pollutants (POPs) have been employed to investigate the association between the largescale atmospheric motions and poleward transports of persistent semi-volatile organic chemicals (SVOCs). We examine the modeled daily air concentration of $\alpha$ - and $\gamma$ hexachlorocyclohexane $(\mathrm{HCH})$ over a period from 1997 through 1999 during which a number of episodic atmospheric transport events were detected in this modeling study. These events provide modeling evidence for improving the interpretation on the cold condensation effect and poleward atmospheric transport of SVOCs in the mid-troposphere. Two episodic transport events of $\gamma-\mathrm{HCH}$ (lindane) to the high Arctic $\left(80-90^{\circ} \mathrm{N}\right)$, one from Asian and another from Eurasian sources, are reported in this paper. Both events suggest that the episodic atmospheric transports occurring in the mid-troposphere (e.g. from $3000 \mathrm{~m}$ to $5500 \mathrm{~m}$ height) are driven by atmospheric horizontal and vertical motions. The association of the transport events with atmospheric circulation is briefly discussed. Strong southerly winds, forced by the evolution of two semi-permanent high pressure systems over mid-high latitudes in the Northern Hemisphere, play an important role in the long-range transport (LRT) of HCHs to the high latitudes from its sources. Being consistent with the cold condensation effect and poleward atmospheric transport in a mean meridional atmospheric circulation simulated by a 2-D atmospheric transport model, as reported by the first part of this study, this modeling study indicates that cold condensation is likely occurring more intensively in the mid-
\end{abstract}

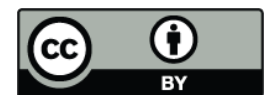

Correspondence to: J. Ma

(jianmin.ma@ec.gc.ca) troposphere where rapid declining air temperature results in condensed phase of the chemical over and near its source regions and where stronger winds convey the chemical more rapidly to the polar region during the episodic poleward atmospheric transport events.

\section{Introduction}

In the accompanying paper (Ma, 2010), we examined the global distillation/cold condensation process and atmospheric transport of semi-volatile pollutants to the Arctic under a mean meridional atmospheric circulation. In that study, a steady state analytic solution and a non-steady steady numerical solution to a two-dimensional atmospheric transport equation model were derived to assess the occurrence of the global distillation/cold condensation effect at higher atmospheric elevations. We summarized that cold condensation may occur in the mid-troposphere over source regions of persistent semi-volatile organic chemicals (SVOCs) in lower and temperate latitudes. Before the chemicals meet cold temperatures and are condensed over high latitudes, frequent atmospheric convection and ascending motion in the source regions carry the chemicals to the midtroposphere where rapid decreasing air temperature and clouds help condense/partition the chemicals from their gasphase to the particle and aqueous phases (aerosols, cloud water droplets and ice particles) and where stronger winds deliver more efficiently the condensed chemicals to the polar region. The continuous descending motion over the high Arctic and the scavenging due to precipitation move subsequently the condensed chemicals to the surface of the Arctic.

Published by Copernicus Publications on behalf of the European Geosciences Union. 
These statements were deduced from the numerical assessments based on the well-known three cells mean atmospheric meridional circulation (Holton, 2004).

In addition to the transport of a pollutant in a mean atmosphere, more realistic atmospheric LRT occur on a daily or weekly basis, e.g., trans-Pacific transport of air pollutants (Jaffe et al., 2003; Holzer et al., 2003; Yienger et al., 2004). This kind of transports is referred to as the episodic atmospheric transport. Up to the late 1980s, the atmospheric level of SVOCs measured over the Arctic was thought to be little influenced by the episodic atmospheric transport ( $\mathrm{Pa}$ cyna and Oehme, 1988), which was deduced based on a little seasonal variation of SVOCs in the polar region. To date, much longer measured time series of SVOCs in the Arctic have shown apparent seasonal variation with a peak during spring (Macdonald et al., 2000). The episodic longrange atmospheric transports of SVOCs on continental- and intercontinental-scale have been reported by recent modeling studies (Ma et al., 2005; Zhang et al., 2008), which occur most often in the spring season, e.g., trans-Pacific transport and the atmospheric transport to the Arctic. These studies have demonstrated that the episodic atmospheric transport is a major pathway of SVOCs. Given that the wind at a higher atmospheric level is much stronger than that near the surface, where the momentum of the wind is considerably dissipated by the surface friction and drag, thereby diminishing the atmospheric transport of pollutants, the most long-range episodic atmospheric transports take place in the free (midhigh) troposphere (Ma et al., 2005; Zhang et al., 2008). On the other hand, the free atmosphere is proven to be the most efficient pathway for the LRT of a substance (Ma, 2010).

Since higher altitudes of the atmosphere are featured by lower air temperature, clouds, and stronger winds that favor the cold condensation and poleward atmospheric transport, in the accompanying paper (Ma, 2010) we have raised a question: in what manner will a chemical migrate to the polar region? A key finding reported in the accompanying paper was that the atmospheric LRT of a persistent SVOC to the Arctic, elevated by a large-scale ascending motion from its sources in tropical latitudes, occurred at 3000-5000 m height of the mean meridional atmospheric circulation, characterized by the three meridional atmospheric cells (Holton, 2004). In the second part of the study, we extend the investigation to the atmospheric transport of SVOC to the Arctic on a daily basis from its sources in the Northern Hemisphere. The objective of this second part investigation is to provide further insight into poleward LRT and global distillation/cold condensation process of the chemical occurring in the mid-troposphere.

Two 3-D atmospheric transport models for persistent toxic substances were employed to identify the atmospheric LRT events for the period from 1997 through 1999, and to provide numerical modeling evidence to our new interpretation on the occurrence of the cold condensation effect in the mid-troposphere. This investigation is also aimed at providing further understanding to the atmospheric dynamics and mechanisms that contribute to the LRT of SVOCs to the high Arctic via the mid-troposphere.

\section{Model and data inputs}

\subsection{Models}

A global three-dimensional atmospheric tracer exchange and transport model, Multicompartment Environmental DIagnosis and Assessment (MEDIA) model (Koziol and Pudykiewicz, 2001), coupled with other modules for explicitly calculating the fate of persistent toxic substances in multi-compartments (such as hydrosphere, soil and cryosphere etc.) for persistent toxic substances has been applied in this numerical investigation. The MEDIA was developed on a spherical Gal-Chen coordinate system with 11 vertical layers from the surface to $15 \mathrm{~km}$ and a horizontal resolution of $2^{\circ} \times 2^{\circ}$ latitude/longitude. The present version of the MEDIA has been extended to $1^{\circ} \times 1^{\circ}$ horizontal spacing and a significant improvement in solving the atmospheric tracer transport equation was made by adopting an embedded advection-diffusion module to transport chemical species (Cote et al., 1998; Zhang et al., 2008). The algorithm was designated in particular for mass conservative for chemicals and has been applied in Canada's Global Environmental Multiscale (GEM) model as well as Canada's regional and global climate models (Cote et al., 1998). The meteorological data driving the model (wind $\left(\mathrm{m} \mathrm{s}^{-1}\right)$, air temperature $(\mathrm{K})$, pressure $(\mathrm{hPa})$, precipitation $\left(\mathrm{mm} \mathrm{h}^{-1}\right.$ converted to $\mathrm{m} \mathrm{s}^{-1}$ ), etc.) at each 30-min time step were obtained by interpolating the 6-hourly objectively analyzed data from the National Centers for Environmental Prediction (NCEP) reanalysis (Kalnay et al., 1996) at standard atmospheric pressure levels. The data were then interpolated to the model grids at $1^{\circ} \times 1^{\circ}$ latitude/longitude and vertical levels of the model. Given that the changes in air concentrations and soil/air exchange in the surface boundary layer are driven partly by atmospheric turbulence which is a sub-grid (both temporal and spatial) process, a non-local and higher order turbulence closure scheme was used in the model to parameterize the sub-grid scale process from coarse resolution meteorological data and detailed underlying surface characteristics (e.g., roughness length, surface drag, geographic height) (Koziol and Pudykiewicz, 2001). The 1-D Jury's model to compute transport, degradation and diffusion processes of a persistent chemical in water, soils, snow and ice (Jury et al., 1983; Koziol and Pudykiewicz, 2001) has been coupled with the atmospheric transport model of the MEDIA. Because transport of pesticides dissolved in oceans is much slower than that in the atmosphere (time scales of the order of years and days respectively) and sparse measurements, following Koziol and Pudykiewicz (2001) we assumed constant ocean concentration of selected substances $(\gamma-\mathrm{HCH}$ in particular) in the present study. Other details for the model can 
be found in Koziol and Pudykiewicz (2001). The MEDIA has been successfully employed in numerical assessment of intercontinental atmospheric transports of POPs (Koziol and Pudykiewicz, 2001; Zhang et al., 2008).

The MEDIA was implemented for the period of 1st December 1996 through 31st December 1999. During this period, a pair of the strongest El Niño and La Niña events for the last half of the 20th century occurred, which have a vigorous influence on interannual variation of POPs (Ma et al., 2004). The MEDIA was performed initially in this period for attempting to assess the response of the atmospheric LRT of SVOCs to the high Arctic to the ENSO (El Niño-Southern Oscillation) events (results will be presented in elsewhere).

The global-scale CanMETOP (Canadian Model for Environmental $T$ ransport of $O$ rganochlorine Pesticides) (Ma et al., 2003; Zhang et al., 2008) was also used in modeling episodic atmospheric transport events. While both CanMETOP and MEDIA are based on the well-known atmospheric advection-diffusion (dispersion) equation, they use different algorithms to discretize the partial differential (advection-diffusion) equation. Another major difference between the MEDIA and CanMETOP is that the CanMETOP is coupled with a Level IV fugacity-based, mass balance soil/air exchange model to compute transport, degradation and diffusion processes of chemicals in soils whereas the MEDIA uses one-dimensional Jury's model to simulate transport in soils. The purpose for application of the two models in this study was primarily to ascertain that the episodic atmospheric transport events can be more faithfully captured and modeled. If the two models, started with the same governing equation for the atmospheric transport but solved with different computational schemes and parameterizations, can duplicate results, the modeled transport events are more close to a realistic reproduction of the actual transport events (Pielke, 2002).

$\alpha$ - and $\gamma$-hexachlorocyclohexane $(\mathrm{HCH})$ are selected in the present modeling study with the focus on $\gamma-\mathrm{HCH}$ (lindane). The model input physical/chemical properties of lindane are from Ma et al. (2003).

\subsection{Emissions}

The newly updated global lindane emission inventory has been applied and verified in the recent modeling study of the global fate and atmospheric transport of the substance (Zhang et al., 2008). Global lindane soil residues at $1^{\circ} \times 1^{\circ}$ latitude/longitude, input as initial conditions of the model integrations, were obtained from a recently updated lindane emission inventory (Zhang et al., 2008) based on global application and accumulation in soils of lindane in and before 1997. The global total soil residues was 13804 tons in 1997. The spatial pattern of the global lindane soil residues is similar to that in 2005 presented by Zhang et al. (2008). The major sources of lindane across the globe can be easily identified in the Canadian Prairies, France, China and India. High soil

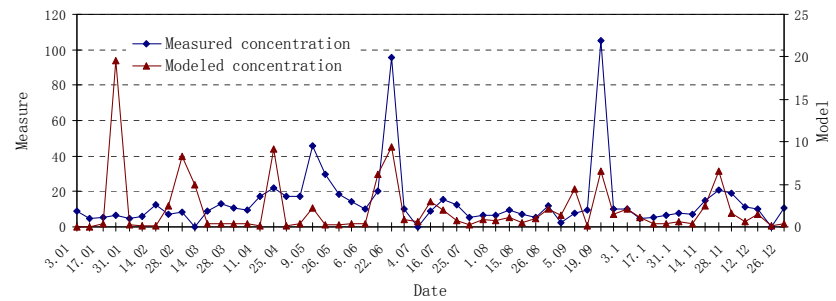

Fig. 1. Daily time series of measured and modeled air concentration $\left(\mathrm{pg} \mathrm{m}^{-3}\right)$ of lindane at Zeppelin Mountain $\left(78^{\circ} 54^{\prime} \mathrm{N}, 11^{\circ} 53^{\prime} \mathrm{E}\right)$ for 1997. The modeled air concentrations are averaged concentrations predicted by the MEDIA and CanMETOP.

residues are also found in Western Africa, Southeast Asia, central Europe and the Great Lake region. Relatively low soil residue of lindane is seen in the Central US, South America and Australia. The model integration is initiated from the soil residue concentration and the chemical is introduced initially into the air only by lindane volatilization simulated by the air/soil exchange (Jury's) model.

Global $\alpha-\mathrm{HCH}$ soil residues at the spatial resolution of $1^{\circ} \times 1^{\circ}$ latitude/longitude in 1997 , developed by $\mathrm{Li}$ et al. (2000), were also applied in this modeling investigation.

\subsection{Model evaluation}

Both the CanMETOP and MEDIA have been evaluated extensively by comparing modeled air concentration of toxic substances with those measured (Ma et al., 2003, 2005; Koziol and Pudykiewicz, 2001; Zhang et al., 2008). To further establish the level of confidence in the present models' results, efforts are made to evaluate and verify the models in predicting the daily variation of the pollutant against those measured, especially the episodic atmospheric transport events. The first dataset used in the evaluation of modeled lindane air concentrations was collected at Zeppelin Mountain $\left(78^{\circ} 54^{\prime} \mathrm{N}, 11^{\circ} 53^{\prime} \mathrm{E}\right)$, Spitsbergen, Norway, an Arctic monitoring site (Berg et al., 2004). Gas phase and aerosol phase SVOCs were sampled once per week at this site. Figure 1 shows measured lindane concentration in the atmosphere $\left(\mathrm{pg} \mathrm{m}^{-3}\right)$ and modeled mean air concentration by the MEDIA and CanMETOP for 1997 at the Zeppelin site. Compared with measured lindane air concentration, both models under-predicted the atmospheric level of the compound near the ground surface by almost one order of magnitude. However, except for the early 1997, both models predicted well the weekly fluctuations of lindane air concentrations. The averaged air concentrations of the CanMETOP and MEDIA correlate well with the measurements at $r=0.70$ $\left(p=8 \times 10^{-8}\right)$.

Under the Canadian-operated Northern Contaminants Program (NCP), using a high volume air sampler air samples of $\mathrm{HCHs}$ have been collected at Alert, $\left(82^{\circ} 30^{\prime} \mathrm{N}, 62^{\circ} 20^{\prime} \mathrm{W}\right)$, Canada. The Alert data provides another high frequency 
measurement of HCHs on a weekly basis in the Arctic (Hung et al., 2002). Compared with the measurements, both models underestimate, again, lindane levels in the atmosphere and appear not to capture well the high concentrations in the late autumn (figure not shown). Though the predicted values are lower than the measurements, the two models capture the weekly changes in the air concentration of the compound during the spring and summertime, especially for the springtime when the poleward long-range atmospheric transport of SVOCs is most prominent, as demonstrated in this study. The modeled air concentrations by the two models associate nicely with the measurement during the spring of 1997 at the correlation of 0.77 for the CanMETOP and 0.56 for the MEDIA, respectively.

It is not fully clear why both models underestimated atmospheric concentrations of $\mathrm{HCHs}$ across the Arctic. In the present simulations the initial air concentrations in the Arctic were assumed to be zero and no background air concentrations due to historical atmospheric and ocean transport and accumulation in the Arctic were implemented into the two models. The modeled atmospheric level in the Arctic was primarily resulted from the atmospheric transport of $\mathrm{HCHs}$ initiated from their sources in low-mid latitudes ( $\mathrm{Li}$ et al., 2000; Zhang et al., 2008). Given the lack of accurate parameterization in the estimate of water/air, snow (ice)/air exchange processes and sparse monitoring data for the level of $\mathrm{HCHs}$ in Arctic ecosystem (e.g., water, ice, snow, vegetation...), the real status and evolution of SVOCs in the Arctic environments were also not yet well understood. Hansen et al. (2006, 2008) provided modeling evidence showing that the presence and melt of snowpack in high latitudes and the Arctic results in seasonal increase in air concentration of SVOCs. Increasing our knowledge and understanding in these aspects may improve considerably atmospheric transport modeling of SVOCs. Nevertheless, given that the weekly changes in lindane concentration in the Arctic atmosphere are associated largely with the LRT, the good correlations between the modeled and measured air concentrations demonstrate that both models could capture well poleward atmospheric transport events.

\section{Transport events in mid-troposphere}

MEDIA modeled daily air concentration of lindane $\left(\mathrm{pg} \mathrm{m}^{-3}\right)$ at the first model level in the air ( $1.5 \mathrm{~m}$ above the surface) from 1st January 1997 to 31st December 1999, averaged over the high Arctic $\left(80-90^{\circ} \mathrm{N}, 1-360^{\circ} \mathrm{E}\right)$, is illustrated in Fig. 2 . Over the three years period the higher air concentration occurred in the springtime, agreeing with the measurements at the Alert Arctic site (Hung et al., 2002). Autumn is another season with high air concentration of HCHs (Hung et al., 2002). The MEDIA did simulate the second higher air concentration during the autumn seasons following the spring seasons, but the mean air concentration in autumns were sub-

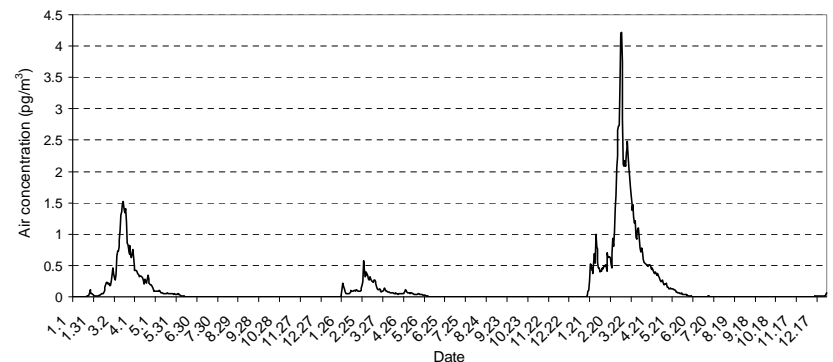

Fig. 2. MEDIA modeled mean daily air concentration $\left(\mathrm{pg} \mathrm{m}^{-3}\right)$ of lindane at the first model level $(30 \mathrm{~m})$ averaged over the high Arctic (1-360 E, 80-90 N) from January 11997 to December 311999.

stantially lower than those in springs. So the focus of this modeling study will be on atmospheric LRT events during the spring seasons. In fact, the poleward LRT of SVOCs occurs most often in the spring season, the transition season between winter and summer. The atmospheric long waves are perturbed frequently by strong meridional exchanges of cold and warm air masses between low and high latitudes during the springtime, thus providing a vehicle for meridional transport of pollutants (Ma et al., 2005; Zhang et al., 2008).

Two prominent peaks of the mean air concentration of lindane over the high Arctic are found in March 1997 and April 1999, respectively (Fig. 2). The mean daily air concentration of lindane in the high Arctic for the spring of 1998 is relatively low due to stronger than normal atmospheric westerly flow across the Northern Hemisphere associated with the strong El Niño event, which weakened considerably the meridional air mass exchange (Ma et al., 2004). In contrast, the highest mean air concentration occurred in the spring of 1999 as the strong La Niña event took place which intensified the meridional atmospheric exchange. Our overall modeling study for the three years period manifests that Eurasia made major contribution to the lindane level in the Arctic air. This result coincides with our previous modeling outcomes which indicated that the European sources made a major contribution to the air concentration of lindane over the high Arctic in 2005, and the contribution from North American sources could be ignored (Zhang et al., 2008).

We examined the two peak events of lindane air concentration occurring in the springs of 1997 and 1999 (Fig. 2) on a daily basis, in order to trace their occurrences, transport routes, and vertical profiles.

\subsection{April 1997 event}

Figure 3 shows superimposed snapshots of the MEDIA modeled mean daily lindane air concentration at the height of $5200 \mathrm{~m}$ once every two days during the period of the event from 30th March to 10th April 1997, overlaid by the mean winds averaged over the same period and at the same height. The higher mean air concentration over the high Arctic can 


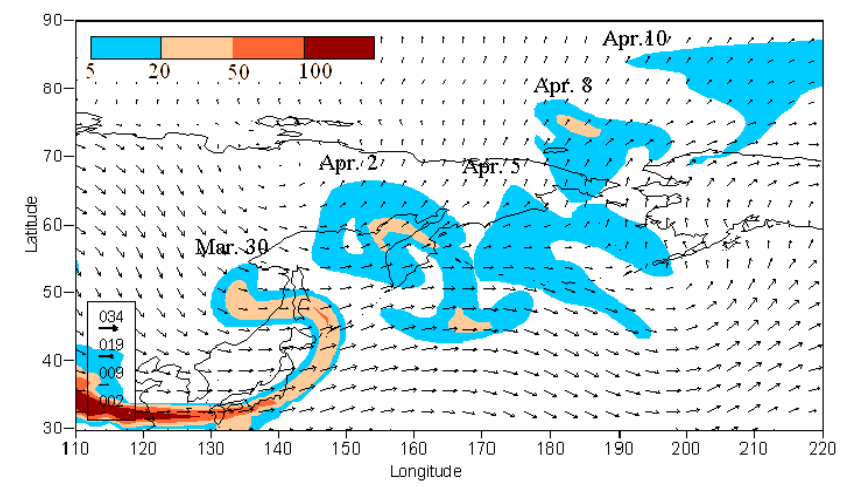

Fig. 3. MEDIA modeled daily lindane air concentration $\left(\mathrm{pg} \mathrm{m}^{-3}\right)$ at about $5200 \mathrm{~m}$ height on selected days over the period 30 March10 April 1997. Figure also shows mean vector winds over the same period and height. The bars at the lower left give wind vectors in knots (Note that 002 mean 2 knots).

be clearly traced back to the Asian sources during this event. Asia has been recognized as an important source region of organochlorine pesticides contributing to their contamination in the western Canadian Arctic and the west coast of Canada by previous atmospheric measurements and numerical modeling studies (Bailey et al., 2000; Koziol and Pudykiewicz, 2001; Harner et al., 2005; Zhang et al., 2008). The soil residue of lindane in Asia $\left(10-60^{\circ} \mathrm{N}, 70-150^{\circ} \mathrm{E}\right)$ accounts for approximately $23 \%$ of the global total residue. Of the total Asian soil residues, $60 \%$ was from East Asia. Pursuing the transport route from Fig. 3 shows that on 30 March the maximum lindane air concentration was located at the east coast of China $\left(30-50^{\circ} \mathrm{N}, 110-140^{\circ} \mathrm{E}\right)$. The air parcel of lindane headed rapidly to the North Pacific Ocean on 2 April under the strong westerly and southwesterly wind regimes. This lindane-laden air, while moving to the International Dateline at $60^{\circ} \mathrm{N}$, was blocked by a ridge of the high pressure, known as the North Pacific high pressure (NPHP) system, centered near Bering Sea and Alaska region (not shown) till 4 April. The NPHP is a semi-permanent high pressure in the North Pacific Ocean. It becomes strongest in the Northern Hemispheric summer and is displaced towards the equator during the winter. When it becomes stronger during the springtime as compared with that in winter and moves to the east, it opens the Arctic directly to Asian pollutants. Given that the atmospheric high pressure circulates the air mass clockwise, the southerly winds on the west of the NPHP then turned the lindane-laden air to the north (5 April). During this period of time, the plume of lindane appeared not to be evidently dispersed, likely attributable to the strong westerly wind and dry atmospheric condition. On 8 April, the intensification and eastward shift of the NPHP towards Alaska forced the lindane-laden air to move further northward to Chukchi Sea. This lindane-laden air was finally delivered to the high Arctic by the southwesterly wind on the west flank of the NPHP system.

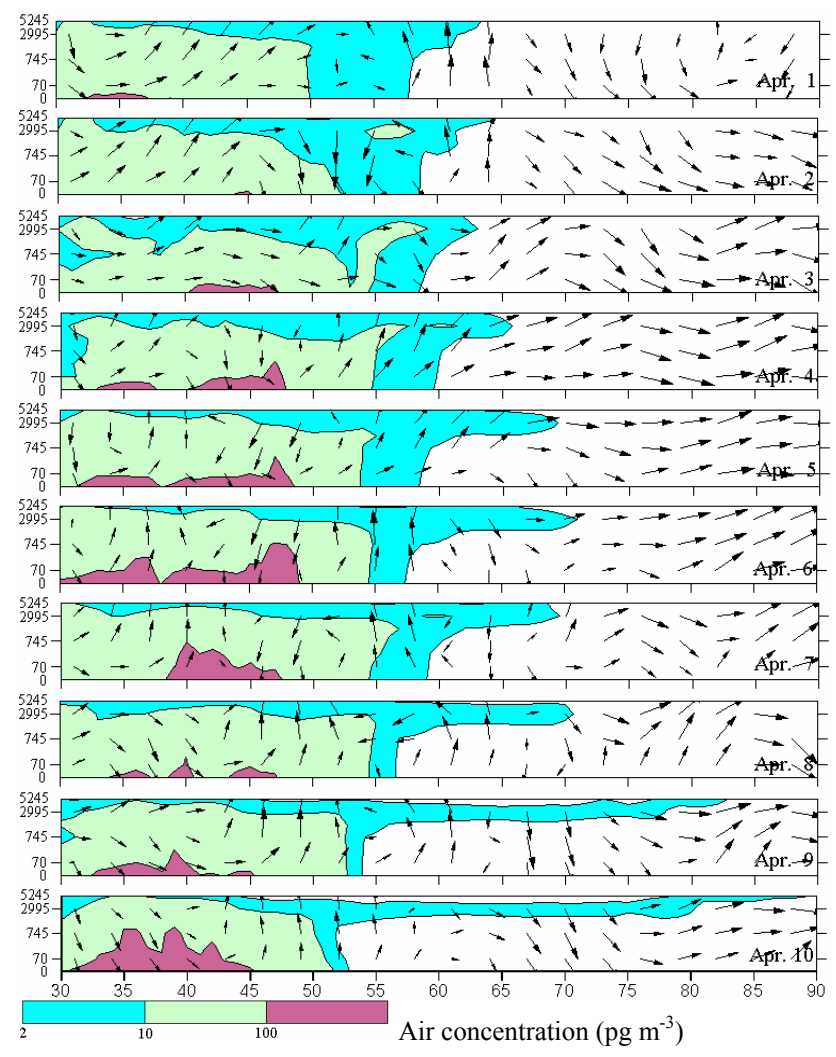

Fig. 4. Vertical cross section of MEDIA modeled mean daily lindane air concentration $\left(\mathrm{pg} \mathrm{m}^{-3}\right)$ from the surface to about $5200 \mathrm{~m}$ model atmospheric height for 1-10 April 1997, averaged over longitude $110^{\circ} \mathrm{E}$ to $140^{\circ} \mathrm{W}$. Figure also shows cross-section of daily mean vector winds by meridional wind and vertical velocity, averaged over the same region and over the same period. In the presentation of the vector winds, the vertical velocity $w$ is multiplied by 100 . Because the MEDIA was established on a pressure $(\sigma-)$ vertical coordinate, the model vertical height (y-axis) was obtained based on the pressure level of the MEDIA.

Although the chemical was emitted from contaminated soils, the model simulations show the presence of high air concentrations of this insecticide at relatively high level of the atmosphere throughout the event. In the accompanying paper (Ma, 2010) we have shown that an ascending motion in the mean atmosphere first lifts a chemical to the midtroposphere, where the chemical is condensed or partitioned under the lower air temperature. The chemical is then transported to the polar region by stronger winds. This process can be also expected to take place during an episodic event. To gain more insight into such the transport pattern in the mid-troposphere during the episodic event, in Fig. 4 we plot the vertical profiles of the modeled daily air concentration crossing $30^{\circ} \mathrm{N}$ to $90^{\circ} \mathrm{N}$ for $1 \mathrm{st}-10$ th April 1997 from the surface to $5200 \mathrm{~m}$, averaged over $110^{\circ} \mathrm{E}$ to $140^{\circ} \mathrm{W}$ which covers the major East Asia source region, North Pacific Ocean, and a large portion of the Arctic. The figure is overlaid by 


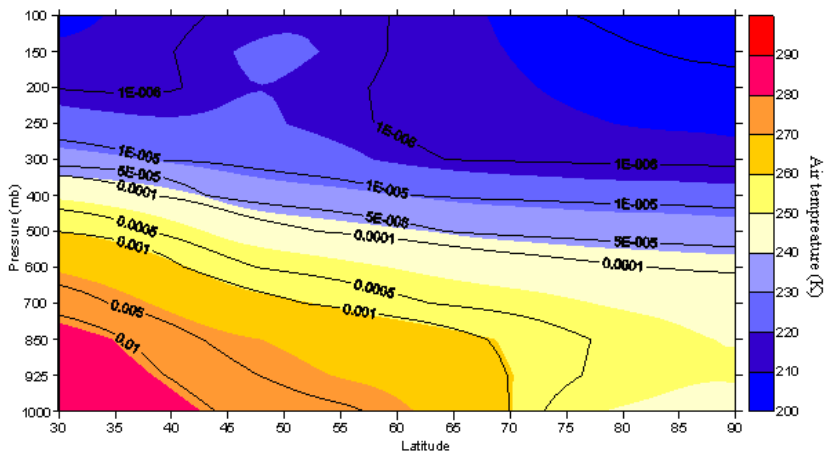

Fig. 5. Vertical cross section of zonal-mean air temperature (K) (color-contoured) and temperature-dependent vapor pressure $(\mathrm{Pa})$ of lindane (solid black line) from the surface to $100 \mathrm{hPa}$, averaged over the period of 1-10 April 1997 and over longitude $110^{\circ} \mathrm{E}$ to $140^{\circ} \mathrm{W}$

the vector winds, generated by the MEDIA input meridional wind and the vertical velocity $\left(\mathrm{Pa} \mathrm{s}^{-1}\right)$. As seen, on April 1, a strong ascending motion took place over the Asian source region $\left(35-50^{\circ} \mathrm{N}\right)$ which carried the lindane-laden air to the mid-troposphere ( $\sim 3000-5000 \mathrm{~m}$, Fig. 4). For the next several days, the ascending motion zone shifted to $50-65^{\circ} \mathrm{N}$. During the northward progress of the upward motion the rising lindane plume remained above the $3000 \mathrm{~m}$ height and moved gradually to the polar region by the southerly winds, a reflection of the southerly flow on the west of the NPHP system. The plume arrived at $65^{\circ} \mathrm{N}$ on 4 April, $70^{\circ} \mathrm{N}$ on 8 April. With the intensification and eastward shift of the NPHP system since 8 April, the plume speeded up and moved all the way to the high Arctic on 9 and 10 April, which can be also identified in Fig. 3. It should be noted that a non-linear color scale was used to scale the air concentration in Fig. 4 in order to detect the signal of the atmospheric transport of the chemical to the Arctic in the mid-troposphere. On the other hand, no notable atmospheric transports are able to be identified at the lower atmospheric level, especially near the surface from our modeling results.

The vertical profile of the zonal-mean air temperature, averaged over $110^{\circ} \mathrm{E}-140^{\circ} \mathrm{W}$ and over 1st-10th April 1997, and the vapor pressure of lindane computed from the zonalmean air temperature are plotted in Fig. 5. The reduction of the vapor pressure to one order of magnitude from 0.01 to $0.001 \mathrm{~Pa}$ occurred over a spatial range from $44^{\circ} \mathrm{N}$ to $70^{\circ} \mathrm{N}$, whereas the same reduction of the vapor pressure in $30^{\circ} \mathrm{N}$ took place merely from $2500-5500 \mathrm{~m}(\sim 750-500 \mathrm{hPa})$, as shown in Fig. 5. For a given relatively strong southerly wind speed of $5 \mathrm{~m} \mathrm{~s}^{-1}$, the declining of lindane vapor pressure from 0.01 to $0.001 \mathrm{~Pa}$ in the horizontal needs about 7 days. With a typical ascending motion at a vertical velocity of $0.001 \mathrm{~m} \mathrm{~s}^{-1}$, the reduction of the vapor pressure from 0.01 to $0.001 \mathrm{~Pa}$ in the vertical only takes about 2 days over warm latitudes. This indicates that a SVOC tends to be more quickly condensed in the vertical atmosphere above their sources in the warm latitude.

Another insight into episodic atmospheric transport of persistent SVOCs to the Arctic in the mid-troposphere can be gained from numerical assessment of $\alpha-\mathrm{HCH}$ for 1997-1999. The global soil residue inventory of $\alpha-\mathrm{HCH}$ (Li et al., 2000) showed that its major source regions were in Asia. The seasonal variation of the MEDIA modeled mean daily air concentrations of $\alpha-\mathrm{HCH}$ averaged over the high Arctic (north of $80^{\circ} \mathrm{N}$ ) for 1997-1999 exhibits the similar patterns as that of lindane, showing higher level of concentration in the atmosphere during springs. While the lowest mean air concentration of $\alpha-\mathrm{HCH}$ in springs in the high Arctic was found in 1998, its highest mean air concentration over the high Arctic appeared in the spring of 1997, rather than the spring of 1999 during which the highest mean air concentration of lindane was modeled. Given that the soil residue accumulated from the past use of $\alpha-\mathrm{HCH}$ in Europe was substantially lower than that of lindane, most major poleward atmospheric transport events of $\alpha-\mathrm{HCH}$ would initiate from its major sources in Asia. This has been demonstrated by poleward atmospheric transport events of $\alpha-\mathrm{HCH}$ for 1997. During this year, the strongest transport event took place, again, in the early April, as shown by Figs. 3 and 4 for lindane, due primarily to the source proximity of two $\mathrm{HCH}$ isomers in Asia and under the same meteorological conditions. The vertical profile of the MEDIA modeled zonal-averaged daily air concentration of $\alpha$-HCH over $110^{\circ} \mathrm{E}-140^{\circ} \mathrm{W}$ is plotted in Fig. 6 . The profile exhibits the similar temporal and spatial patterns as that for lindane, showing daily progress of $\alpha-\mathrm{HCH}$ to the Arctic in the mid-troposphere.

\subsection{March 1999 event}

Different from the April 1997 event, this event for the poleward episodic atmospheric transport of lindane, characterized by the highest mean air concentration over the high Arctic (Fig. 2), occurred over Eurasia spanning from $0-90^{\circ} \mathrm{N}$ (East Asia not included). The soil residue of lindane in this region accounts for more than $40 \%$ of the global total residue. Compared to the East Asian major sources, the European sources were in higher latitudes $\left(40-55^{\circ} \mathrm{N}\right)$. The event was originated from Western Europe in the late February 1997. Lindane-laden air was driven by a strong middlelatitude southwesterly flow to the common borders between European and Asian continents $\left(50-60^{\circ} \mathrm{E}\right)$ where the local sources also made a contribution to the plume in the beginning of March. To illustrate the atmospheric pathway of lindane from Eurasia to the Arctic, we present selected daily air concentration modeled by the MEDIA during the late phase of the transport event from 27 February to 8 March. Figure 7 plots the snapshots of the selected daily lindane air concentration at about $5200 \mathrm{~m}$ model level, overlaid by the mean horizontal vector winds, averaged over the same period and at the same level, showing the footprints of the lindane-laden 


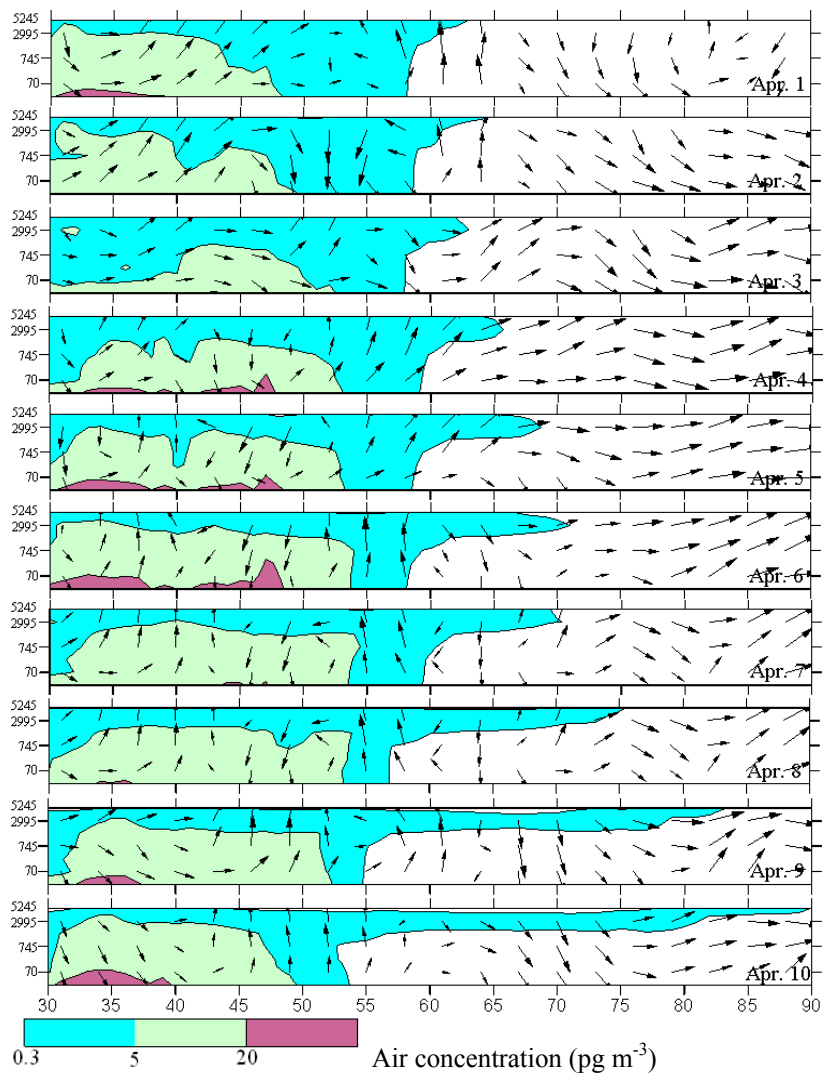

Fig. 6. Vertical cross section of MEDIA modeled zonal-mean daily $\alpha-\mathrm{HCH}$ air concentration $\left(\mathrm{pg} \mathrm{m}^{-3}\right)$ from the surface to $5200 \mathrm{~m}$ height for 1-10 April 1997, averaged over longitude $110^{\circ} \mathrm{E}$ to $140^{\circ} \mathrm{W}$. Figure also shows cross-section of daily zonal-averaging vector winds by mean meridional wind and vertical velocity over the same region and over the same period. In the presentation of the vector winds, the vertical velocity $w$ is multiplied by 100 .

air during the period of the event. The plume, originated from West Europe, was stretched by a southwesterly wind extending from West Europe to Mid Asia, northward between Black Sea and Caspian Sea on 27 February. Along with the westward shift of the Siberia high pressure (another semi-permanent high pressure system in the Northern Hemisphere), the southerly flow on the west of the high pressure pushed the lindane-laden air over Barents Sea via western Russia on 2 March, which then spread out over the Arctic Ocean on 5 March. The plume was eventually moved to the high Arctic on 8 March but somewhat dissipated.

While the source of the chemical was in the contaminated soil, enormous amount of the chemical was present in the mid-troposphere $(\sim 5000 \mathrm{~m})$ during the event. Because the northward moving warm air climbed over the cold West Siberia air, it is expected that this forced large-scale ascending motion would lift the chemical to a higher atmospheric altitude. Figure 8 illustrates the vertical cross-section of the zonal-averaged $\left(1-90^{\circ} \mathrm{E}\right)$ air concentration from $1 \mathrm{st}$

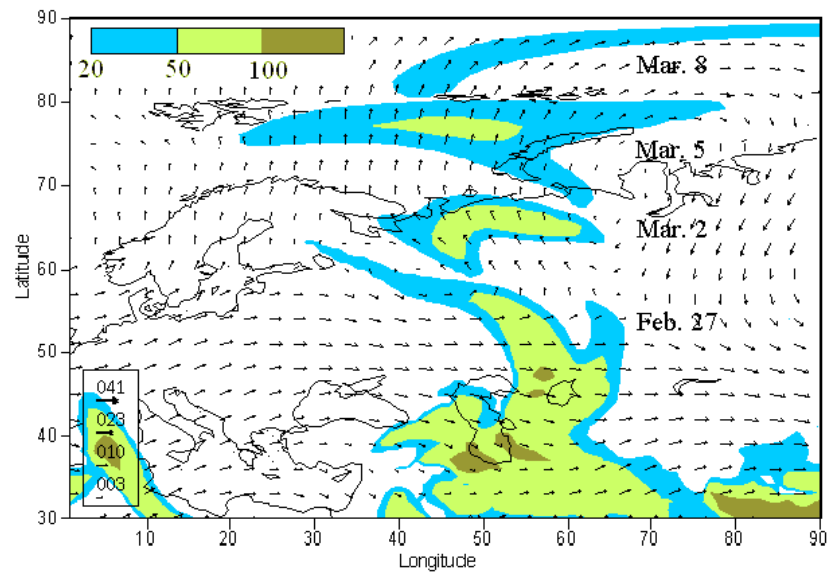

Fig. 7. Same as Fig. 2 but for 1-8 March 1999 and the region of $1-90^{\circ} \mathrm{E}$.

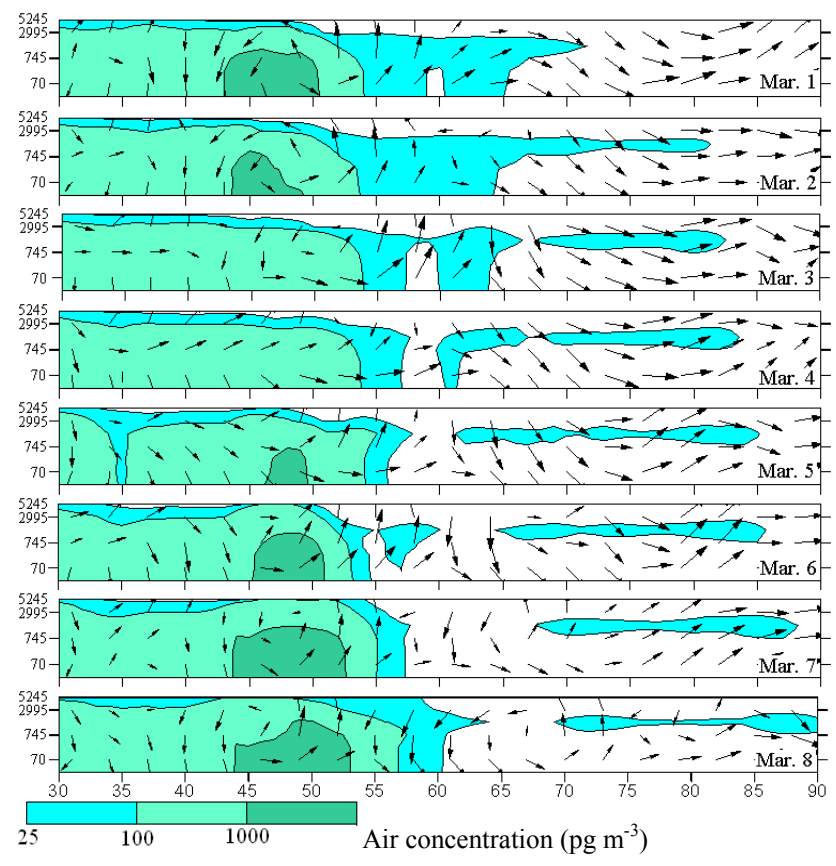

Fig. 8. Same as Fig. 3 for 1-8 March 1999 and the region of 1$90^{\circ} \mathrm{E}$.

to 8th March, simulated by the MEDIA and superimposed by the zonal-averaged vector winds which are composed of the meridional wind and the vertical velocity averaged over the same region $\left(1-90^{\circ} \mathrm{E}\right)$. As shown, an upward motion remained in the north $\left(50-60^{\circ} \mathrm{N}\right)$ of the West European source region, centered near $45-50^{\circ} \mathrm{N}$ until $7 \mathrm{March}$, which elevated the lindane-laden air to an atmospheric height at about $3000 \mathrm{~m}$. Above this level, a southerly wind, as a signature of the southerly flow on the west side of the Siberia high pressure, delivered the chemical all the way to the Arctic. 


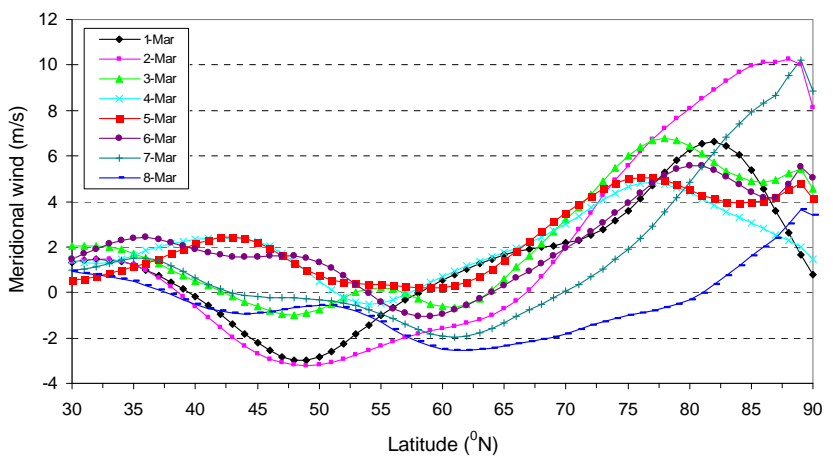

Fig. 9. Zonal-mean daily meridional wind $v\left(\mathrm{~m} \mathrm{~s}^{-1}\right)$ at $500 \mathrm{hPa}$ $(\sim 5500 \mathrm{~m})$, averaged over longitude $1-90^{\circ} \mathrm{E}$ during $1-8$ March 1999. $v>0$ denotes southerly wind and $<0$ denotes northerly wind.

We again used a non-linear color scale in Fig. 8 to distinguish the signal of the atmospheric transport of the chemical to the Arctic at the high atmospheric altitude. On the other hand, notable atmospheric transport of the chemical at the lower atmospheric level was almost invisible during this event. Given that the large-scale southerly wind regime plays a very important role in the upward and northward transport of the chemical, Fig. 9 presents the measured daily mean meridional wind component (the wind speed greater than zero denotes southerly wind and vise versa) from $30-90^{\circ} \mathrm{N}$ during the event at $5500 \mathrm{~m}$ height averaged over Eurasia region, extending from $1-90^{\circ} \mathrm{E}$. The southerly wind regime started to build up near $55^{\circ} \mathrm{N}$ on 1 st March and extended northward to the Arctic. As seen, the wind regime intensified towards the Arctic, suggesting that the journey of the lindane-laden air to the Arctic would speed up after it moved over the Arctic Ocean.

Similar to Fig. 5 for the April 1997 Asian transport event, both the air temperature and vapor pressure of lindane declined with the increasing height and latitude during this event. While the chemical was likely condensed from vapor to particle phase in north of $50^{\circ} \mathrm{N}$ subject to lower air temperatures and more clouds (Ma, 2010), it may be condensed even more quickly in the vertical over its source region via the large-scale ascending motion (figure not shown).

\subsection{CanMETOP modeling of April 1997 transport event}

To verify the MEDIA modeling results presented above, the global-scale CanMETOP (Ma et al., 2003; Zhang et al., 2008) was also implemented for the same period (1st December 1996-31st December 1999). Figure 10 shows CanMETOP modeled vertical profile of zonal-averaged daily air concentration of lindane over $110^{\circ} \mathrm{E}-140^{\circ} \mathrm{W}$ for 1 st-10th April 1997, depicting the Asia transport event. Although the CanMETOP uses a different vertical coordinate and hence has a different vertical structure from MEDIA, the modeled vertical profile during the event captured the similar pattern



Fig. 10. Vertical cross section of CanMETOP modeled zonal-mean daily lindane air concentration $\left(\mathrm{pg} \mathrm{m}^{-3}\right)$ from the surface to $7000 \mathrm{~m}$ height for 1-10 April 1997 (from top to bottom), averaged over longitude $110^{\circ} \mathrm{E}$ to $140^{\circ} \mathrm{W}$.

as that simulated by the MEDIA (Fig. 4), showing the strong transport of lindane to the Arctic via the mid-troposphere $(3000-5000 \mathrm{~m})$. This reinforces our confidence in the modeled episodic transport events.

\section{Conclusions}

In addition to the atmospheric transport of persistent, semivolatile chemicals to the Arctic in a mean meridional atmospheric circulation as presented in the accompanying paper (Ma, 2010), the present work illustrates that the episodic poleward atmospheric transport and cold condensation process under daily atmospheric activities also occurred mostly in the mid-troposphere over the source regions of the chemicals or warm and temperate regions. The large-scale 
ascending motions associated with the two events reported here moved HCHs-laden air to the mid-troposphere once the pollutants started their journey to the Arctic. Given that the warm air in lower and temperate latitudes always climbs over the cold air in northern latitudes, such large-scale ascending motions would always take place either in the mean atmosphere (Ma, 2010) or in the daily atmospheric motion as described in this paper. It should be emphasized that the present study focused largely on the major atmospheric pathways associated with cold condensation and the poleward atmospheric transport but paid less attention to the thermodynamic and chemical/physical properties of the chemicals. The later has been extensively studied (e.g., Wania and Mackay, 1993) elsewhere and depicted in the accompanying paper (Ma, 2010). Aiming at improving the interpretation on global distillation/cold condensation, this study reveals that rapid decline of air temperature with height, raised by the frequent occurring upward motions in warm latitudes, leads to rapid condensation/partition of vapour phase chemicals. Stronger (southerly) winds in the mid-troposphere delivered more efficiently the condensed chemicals to the polar regions.

Acknowledgements. This study is funded by the International Polar Year program: Intercontinental Atmospheric Transport of Anthropogenic Pollutants to the Arctic.

Edited by: A. S. H. Prévôt

\section{References}

Bailey, R., Barrie, L. A., Halsall, G. J., and Muir, D. C. G.: Atmospheric organochlorine pesticides in the western Canadian Arctic: Evidence of trans-Pacific transport, J. Geophys. Res., 105, 11805-11811, 2000.

Berg, T., Kallenborn, R., and Manø, S.: Temporal trends in atmospheric heavy metal and organochlorine concentrations at Zeppelin, Svalbard, Arct. Antarct. Alp. Res., 36, 284-291, 2004.

Cote, J., Gravel, S., Methot, A., Patoine, A., Roch, M., and Staniforth, A.: The operational CMC-MRB global environmental multiscale (GEM) model. Part I: Design considerations formulation, Mon. Weather Rev., 126, 1373-1395, 1998.

Hansen, K. M., Halsall, C. J., Christensen, J., Brandt, J., Frohn, L. M., Geels, C., and Skjøth, C. A.: The role of the snowpack on the fate of $\alpha-\mathrm{HCH}$ in an atmospheric chemistry-transport model, Environ. Sci. Technol., 42, 2943-2948, 2008.

Hansen, K., Halsall, C. J., and Christensen, J.: A dynamic model to study the exchange of gas-phase POPs between air and a seasonal snowpack, Environ. Sci. Technol., 40, 2644-2652, 2006.

Harner, T., Shoeib, M., Kozama, M., and Li, S. M.: Hexachlorocyclohexanes and endosulfans in urban, rural, and high altitude air samples in the Fraser Valley, British Columbia: Evidence for trans-Pacific transport, Environ. Sci. Technol., 39, 724-731, 2005.

Holton, J. R.: An Introduction to Dynamic Meteorology, Elsevier Academic Press, Burlington, MA, USA, 535 pp., 2004.
Holzer, M., McKendry, I. G., and Jaffe, D. A.: Springtime transPacific atmospheric transport from East Asia: A transit-time probability density function approach, J. Geophys. Res., 108 (D22), 4708, doi:10.1029/2003JD003558, 2003.

Hung, H., Halsall, C. J., Blanchard, P., Li, H. H., Fellin, P., Stern, G., and Rosenberg, B.: Temporal trends of organochlorine pesticides in the Canadian Arctic atmosphere, Environ. Sci. Technol., 36, 862-868, 2002.

Jaffe, D. A., McKendry, I. G., Anderson, T., and Price, H.: Six "new" episodes of trans-Pacific transport of air pollutants, Atmos. Environ., 37, 391-404, 2003.

Jury, W. A., Spencer, W. F., and Farmer, W. J.: Behavior assessment model for trace organics in soil: I. Model description, J. Environ. Qual., 12, 558-564, 1983.

Kalnay, E., Kanamitsu, M., Kistley, R., and coauthors.: The NCEP/NCAR reanalysis project, Bull. Am. Meteorol. Soc., 77, 437-471, 1996.

Koziol, A. S. and Pudykiewicz, J. A.: Global-scale environmental transport of persistent organic pollutants, Chemosphere. 45, 1181-1200, 2001.

Li, Y. F., Scholdz, M. T., and van Heyst, B. J.: Global gridded emission inventory of $\alpha$-hexachlorocyclohexane, J. Geophys. Res., 105(D5), 6621-6632, 2000.

Ma, J., Daggupaty, S. M., Harner, T., and Li, Y. F.: Impacts of lindane usage in the Canadian prairies on the Great Lakes ecosystems1: Coupled atmospheric transport model and modeled concentrations in air and soil, Environ. Sci. Technol., 37, 37743781, 2003.

Ma, J., Hung, H., and Blanchard, P.: How do climate fluctuations affect persistent organic pollutant distribution in North America? Evidence from a decade of air monitoring, Environ. Sci. Technol., 38, 2538-2543, 2004.

Ma, J., Venkatesh, S., Li, Y., Cao, Z., and Daggupaty, S.: Tracking toxaphene in the North American Great Lakes basin - 2. A strong episodic long-range transport event, Environ. Sci. Technol., 39, 8123-8131, 2005.

Ma, J.: Atmospheric transport of persistent semi-volatile organic chemicals to the Arctic and cold condensation effect in the midtroposphere - Part 1: 2-D modeling in mean atmosphere, Atmos. Chem. Phys., 10, 7303-7314, doi:10.5194/acp-10-73032010, 2010.

Macdonald, R.W., Barrie, L. A., Bidleman, T. F., Diamond, M. L., Gregor, D. J., Semkin, R. G., Strachan, W. M. J., Li, Y. F., Wania, F., Alaee, M., Alexeeva, L. B., Backus, S. M., Bailey, R., Bewers, J. M., Gobeil, C., Halsall, C. J., Harner, T., Hoff, J. T., Jantunen, L. M. M., Lockhart, W. L., Mackay, D., Muir, D. C. G., Pudykiewicz, J., Reimer, K. J., Smith, J. N., Stern, G. A., Schroeder, W. H., Wagemann, R., and Yunker, M. B.: Sources, occurrence and pathways of contaminants in the Canadian Arctic: A review, Sci. Total Environ., 254, 93-236, 2000.

Pacyna, J. M. and Oehme, M.: Long-range transport of some organic compounds to the Norwegina Arctic, Atmos. Environ., 22, 243-257, 1988.

Pielke, R. A.: Mesoscale meteorological modeling, Academic Press, San Diego, CA, USA, 704 pp., 2002.

Wania, F. and Mackay, D.: Global fractionation and cold condensation of low volatility organochlorine compounds in Polar Regions, Ambio., Stockholm [AMBIO.], 22(1), 10-18, 1993.

Yienger, J. J., Galanter, M., Holloway, T. A., Phadnis, M. J., Gut- 
tikunda, S. K., Carmichael, G. R., Moxim, W. J., and Levy II, H.: The episodic nature of air pollution transport from Asia to North America, J. Geophys. Res., 105, 26931-26945, 2000.
Zhang, L., Ma, J., Venkatesh, S., Li, Y. F., and Cheung, P.: Modeling evidence of episodic intercontinental long-range transport of lindane, Environ. Sci. Technol., 42, 8791-8797, 2008. 